\title{
Future employment of allopathic medical graduates
}

\author{
Employment prospects and the status of private sector health care need to be developed
}

\author{
Ceylon Medical Journal, 2000; 45: 6-8
}

\section{Introduction}

In Sri Lanka, doctors did not have any anxieties about employment for the last three decades. Anxiety about employment developed in the latter half of 1999 when the Minister of Health declared the batch of doctors who had just finished the internship could not be absorbed because the "cadre was full". At the time of writing, these doctors have been asked to remain in their positions, but their service grades have not been defined.

The health care system of Sri Lanka is complex. We have three legally recognised systems of medicine: allopathy, homeopathy and Ayurveda, with their respective medical councils as defined in Medical Ordinance, Homeopathic Act and Ayurvedic Act. Allopathic doctors are of two categories, the assistant medical officers (AMOs) and medical officers (MOs). The AMOs after a stipulated period of satisfactory service, are registered under the section 41 of the Medical Ordinance. The MOs are medical graduates who are registered under the section 29 after satisfactory completion of one year's internship. Once the registration is secured AMOs are referred to as registered medical officers (RMOs). RMOs/AMOs have received less training than medical graduates. They are, however, very useful and reasonably competent in delivering primary health care. The private sector health care in Sri Lanka has received little recognition or control of the state. It comprises personnel of all three systems. In addition, there are quacks who pose as allopathic practitioners. It is difficult to conduct a census of quacks but their number is about 30000 .

Because of this complex situation, statistics are interpreted to suit different agendas when discussing employment. In this context Mark Twain's words "There are three kinds of lies; lies, damn lies and statistics" comes to mind.

In colonial Ceylon the government was not regular in appointing doctors to the government service. From late 1940s to late 1960s doctors did not have any difficulty in securing employment in the state sector. In the 1960s the Minister of Health declined to employ doctors in state service as the cadre was full. This resulted in doctors leaving the country in search of employment. At the time employment prospects for Ceylonese doctors was plentiful in western countries. They were better paid than their counterparts employed in Ceylon. This prompted even doctors who had employment in the state sector to leave the country, result- ing in a dearth of doctors in Sri Lanka in the 1970s. Since then there has been no problem for newly qualified medical graduates to secure employment in the state sector until the present crisis.

\section{Doctor-population ratio}

In 1997 the state employed 5628 medical graduates (1). In the private sector we have about 6000 medical graduates in active practice. The mid-year population of the year was 18 million (2). This works out to one medical graduate for every three thousand people. If we consider RMOs too as doctors, there were 1384 of them in state service in 1997 (1), and in the private sector about 1700, making the total number of doctors in the island about 8700. This amounts to one doctor available for about 2100 people. Compared to other developing countries this a quite satisfactory ratio.

\section{State sector employment of medical graduates}

Only $1.6 \%$ the gross national product (GNP) has been spent on health in 1997 (1) and just 2.3\% in 1989 (1). WHO recommends $5 \%$ of GNP as a reasonable proportion to be invested in health (3). So we seem to be spending too little on health care and the proportion of GNP spent on health seems to be on the decline. The present cadre structure has been designed about 20 years ago, and does not reflect present day needs. A cabinet memorandum (4) prepared by the Ministry of Health recommends an increase of medical officer cadre by 9682 from 1999 to 2005 and by a further 7147 from 2006 to 2010 (4). If the memorandum is implemented, medical graduates will not have any difficulty in securing state employment for the next decade. Increase in cadre must mean an increase in infrastructure too. Considering the challenges we have to face in the near future infrastructure needs rapid development. Aspects such as geriatrics, sports medicine and occupational health have received little or no attention up to now in our health care system. The state has a moral obligation to revise the existing cadre structure and employ many more medical graduates.

A question arises whether to train any more RMOs. It is a fact that RMOs have proved useful to maintain the health service during trade union actions of state doctors. One cannot deny also their contribution to delivering 
primary health care in rural areas. However, there is no future necessity for two categories of doctors. The undergraduate medical curriculum should ensure that newly qualified doctors are suited to deliver primary health care even in remote rural areas of Sri Lanka.

The state spends a tidy sum to produce medical graduates. A medical graduate remaining unemployed is a waste of resources. An employed medical graduate will contribute to the health of the nation and adds saved man hours otherwise lost due to illness or poor health. Forty years ago all graduates were certain of state employment. In the mid-1960s arts graduates found it difficult to find state employment. Subsequently, the state found it difficult to employ even all the science graduates. The latest victims are the dental graduates. In $199818.9 \%$ of those qualified GCE " $A$ " level or above were unemployed (2). In the circumstances, one may question whether it is morally justifiable for only the medical graduates to clamour for state employment.

\section{An alternative source of employment: the private sector}

If the state cannot employ all newly qualified medical graduates an alternative source of employment will be the private sector. The private sector must be developed sufficiently to handle this need. As it is, the bed strength of private sector is only 2500 (2). In addition to this there are about 1000 family practices manned by either medical graduates or RMOs. Measures to enhance the scope of the private sector as a potential future employer for newly qualified medical graduates and to supplement the state sector in providing health care to the people require urgent attention.

Family doctors should have designated and official access to the state sector hospitals. All citizens should have a health document where all care offered, both in the private sector and the state sector are recorded. This will help to give better recognition to the private sector and prevent duplication of work, which leads to waste of resources.

\section{Desirable changes in private health care institutions}

As there is no proper referral system at present in the private sector, secondary and tertiary care specialists attend on problems that could be dealt with effectively by primary care physicians. This puts an unnecessary workload on the former, depriving them of time that can be used on more useful pursuits such as teaching and research. At the same time, it reduces the scope for primary care physicians, and increases unnecessarily the expenditure for patients. Currently there is valid criticism about the quality and cost of care (5) in the private sector. Quality of care may be regulatable to some extent by the Private Medical
Institutions (Registration) Act which has been presented in Parliament, and is awaiting concurrence of Provincial Councils at the time of writing (6). Better state recognition of the private sector contribution also seems to be necessary. Staff in the private sector are poorly trained. The problem has been identified by the state, but remains uncorrected (2).

\section{Postgraduate studies for private sector doctors}

As of now, the only course of study available for private sector doctors in the Postgraduate Institute of Medicine is the diploma in family medicine. Few obtain a doctorate in family medicine by thesis. In addition to this the College of General Practitioners provides a study course and holds an examination to acquire its membership. Potential to specialise in most disciplines should be available to doctors in the private sector. This facility could be made available without sacrificing standards of postgraduate medical education or the diplomas awarded.

\section{Elimination of quacks}

A quack engages in a professional activity which he is not entitled to engage in, and is a serious threat to the health of patients who seek his services. A quack deprives the legitimate person engaging in the profession of health care and poses a disincentive to young doctors who want to get into family practice. Medical associations, the Sri Lanka Medical Council, medical student bodies and Police must join hands to achieve this. The "traditional Chinese medical practitioners" are also quacks, for "Chinese medicine" is not legally acceptable in Sri Lanka.

\section{Phased withdrawal of state health care personnel from the private sector}

A state sector doctor working in the private sector has two jobs. When employment is a problem it is not rational for one person to have two jobs. Since specialists in certain disciplines are scarce in the private sector, withdrawal of state sector doctors from the private sector has to be carried out only in stages (7).

\section{Prevention of Ayurvedic and homeopathic practitioners prescribing allopathic drugs}

Ayurvedic and homeopathic practitioners pose as allopathic practitioners and prescribe allopathic medicines. This has the same effect as that of quacks on the employment prospects of medical graduates and on patient welfare. This may have to be dealt with by Medical Councils of all three systems of medicine working together.

Young doctors willing to set up family practices should be offered low interest loans by state banks. State owned 


\section{Leading article}

buildings (eg. part of a supermarket building or a community service building) may be offered to young doctors at a low rental and on a priority basis. Duty concessions may be offered to purchase a motor vehicle, as well as equipment necessary to establish a family practice.

\section{Conclusions}

Doctors' associations should continue to persuade the state to employ as many allopathic doctors as possible. The medical profession must make the authorities realise that a good health service increases the productivity of the nation and contributes for healthy growth of the economy. Health deserves a much bigger financial allocation than at present to provide more employment to allopathic medical graduates. As an alternative source of employment the private sector should be improved, recognised, and made more responsible and accountable. What we persuade government to do in the first two decades of the twenty first century will be an important determinant of the destiny of future aleopathic medical graduates, and the health of our nation.

\section{References}

1. Annual Health Bulletin. Ministry of Health, 1997.

2. Annual Report. Central Bank of Sri Lanka, 1998.

3. Health, Nutrition and Population: Sector Strategy. World Bank, 1995.

4. Cabinet memorandum. Ministry of Health, 1999.

5. Report of the National Workshop on Quality of Health Care. September, 1998.

6. Private Medical Institutions (Registration) Act of 1997 (draft).

7. Summary of Recommendations: Presidential Task Force on Health Policy Implementation, 1999.

B G D Bujawansa, Family Physician, Dehiwala South, Sri Lanka.

\section{It's true. Asians can't think}

Asia must not merely reflect on why Western thoughts shape the world we know, it must also ask why so many Asian minds flourish only after they have gone to the West. For evidence, just look at the many Nobel Prizes won by Asians living and working in America. Time and again, talented émigrés say they had to leave Asia because the intellectual atmosphere was stifling or because the established hierarchy respected seniority over brains.

Blaming Asian schools for focusing on memorization - as opposed to "thinking"- is too pat an excuse, as schools and universities reflect the basic values of a society. It is ingrained in the Asian psyche that "correct" answers always exist and are to be found in books or from authorities. Teachers dispense truth, parents are always right and political leaders know better. In executive-led societies such as China and Hong Kong, leaders act like philosopher-kings, often uttering unchallenged banalities. Senior officials sometimes resemble the powerful palace eunuchs of past dynasties: imperial, unaccountable, incompetent. Questioning authority, especially in public, is disrespectful, un-Asian, un-Confucian.

Shaw S. Time May 31, 1999, p 23. 